\title{
BMJ Open The Brabant study: design of a large prospective perinatal cohort study among pregnant women investigating obstetric outcome from a biopsychosocial perspective
}

Margreet Meems (D) , ${ }^{1}$ Lianne Hulsbosch, ${ }^{1}$ Madelon Riem, ${ }^{1}$ Christina Meyers, ${ }^{2}$ Tila Pronk, ${ }^{3}$ Maarten Broeren, ${ }^{4}$ Karin Nabbe,${ }^{5}$ Guid Oei, ${ }^{6}$ Stefan Bogaerts, ${ }^{7}$ Victor Pop ${ }^{1}$

To cite: Meems M, Hulsbosch L, Riem M, et al. The Brabant study: design of a large prospective perinatal cohort study among pregnant women investigating obstetric outcome from a biopsychosocial perspective. BMJ Open 2020;10:e038891. doi:10.1136/ bmjopen-2020-038891

- Prepublication history for this paper is available online. To view these files, please visit the journal online (http://dx.doi. org/10.1136/bmjopen-2020038891).

Received 27 March 2020 Revised 10 September 2020 Accepted 30 September 2020

Check for updates

(c) Author(s) (or their employer(s)) 2020. Re-use permitted under CC BY-NC. No commercial re-use. See rights and permissions. Published by BMJ.

For numbered affiliations see end of article.

Correspondence to

Dr Victor Pop;

V.J.M.Pop@tilburguniversity.edu

\section{ABSTRACT}

Background Pregnancy is characterised by many biological and psychosocial changes. Adequate maternal thyroid function is important for the developing fetus throughout gestation. Latent class analyses recently showed three different patterns of change in thyroid function throughout pregnancy with different associations with obstetric outcome. Maternal distress during the pregnancy (anxiety and depression) negatively affects obstetric outcome. Pregnancy distress in turn may be affected by personality traits and attachment styles. Moreover, during the pregnancy, substantial social changes occur in the partner relationship and work experience. The aim of the Brabant study is to investigate the association between thyroid function trajectories and obstetric outcomes. Moreover, within the Brabant study, we will investigate how different trajectories of pregnancy distress are related to obstetric outcome, and the role of personality in this association. We will evaluate the possible role of maternal distress and attachment style on maternal-fetal bonding. Finally, we will study social changes in the perinatal period regarding partner relationship and well-being and performance at work. Methods and analysis The Brabant study is a Iongitudinal, prospective cohort study of an anticipated 4000 pregnant women. Women will be recruited at 8-10 weeks gestation among community midwife practices in South-East Brabant in the Netherlands. Thyroid function parameters (TSH and fT4), thyroid peroxidase antibody and human chorionic gonadotrophin will be assessed at 12, 20 and 28 weeks gestation. Moreover, at these three time points women will fill out questionnaires assessing demographic and obstetric features, life style habits and psychological and social variables, such as depressive symptoms, personality, partner relationship quality and burnout. Data from the obstetric records will also be collected.

Ethics and dissemination The study has been approved by the Medical Ethical Committee of the Máxima Medical Center Veldhoven. Results will be submitted to peerreviewed journals in the relevant fields and presented on national and international conferences.
Strengths and limitations of this study

- Prospective design with three measurements of both biological and psychological variables during the pregnancy, which enables the use of latent class analysis.

- A multifactorial approach.

- A large sample size.

- Use of self-report with validated questionnaires instead of interviews.

\section{INTRODUCTION}

Pregnancy is a life-changing event characterised by substantial physiological, psychological and social changes, which can have an impact on the physical and mental health of pregnant women, partner relationships and work.

\section{Maternal thyroid function}

Adequate maternal thyroid function is important during pregnancy, both for mother and fetus. Impaired thyroid function has been associated to various obstetric problems including preterm birth (PTB), gestational diabetes (GD), small for gestational age (SGA), abnormal fetal position and pre-eclampsia (PE) ${ }^{1-3}$ Some studies have observed an association between outcomes and both TSH and fT4, whereas others have reported a relationship either with TSH but not fT4 or vice versa. ${ }^{4}$ Similarly, studies investigating the consequences of maternal thyroid dysfunction on infant neurodevelopment have reported disparate findings. ${ }^{2}$ Such inconsistencies have always been difficult to reconcile but may result from the use of thyroid function reference ranges derived from cross-sectional data. 
This cross-sectional approach does not address longitudinal changes in thyroid function that occur in individual women during the course of their pregnancy. It is likely, therefore, that more accurate information can be obtained if longitudinal TSH and fT4 measurements from the same women during each trimester are used in epidemiological studies. Latent class analysis (LCA) is a statistical approach to model temporal changes within heterogeneous population samples. ${ }^{6}$ This technique has extensively been discussed in detail elsewhere using thyroid function data collected during pregnancy between 2003 and $2004(\mathrm{n}=1100)$. This resulted in new insights of three thyroid function trajectories, assessed at each trimester throughout pregnancy, taking both TSH and fT4 into account. ${ }^{7}$ Preliminary further analysis of these data showed that women of two trajectories (representing $8 \%$ of the total sample) were at risk for obstetric complications including PE, PTB, SGA and abnormal fetal position at birth (breech) compared with the reference group. However, the power of these analyses was low, especially when performed in primiparous and multiparous women separately. Also, human chorionic gonadotrophin (hCG) assessments were not performed. A recent study showed that the beneficial effect of hCG on fT4 production is hampered in thyroid peroxidase antibody (TPO-Ab) positive women. ${ }^{8}$ Therefore, future LCA should also take into account the assessment of hCG.

Because important obstetric complications such as PE, PTB, breech position and SGA show a relatively low incidence rate $(5 \%-10 \%)$ and primiparous women are at substantial higher risk compared with multiparous women, large samples are needed to evaluate possible associations in two distinct groups.

\section{Maternal mental health: mental distress}

Pregnancy is characterised by many changes and adaptations, most of which are outside of the woman's control (eg, bodily changes and physical complaints). Within a vulnerability-stress model, all these physical, physiological and psychosocial changes could trigger pregnancy distress symptoms (depressive and negative affect (NA) symptoms) in already vulnerable women. ${ }^{9}$ Depressive symptoms during the pregnancy are common and affect up to $20 \%$ of the childbearing women, ${ }^{10}$ also in Dutch pregnant populations. ${ }^{11}$ The prevalence for self-reported anxiety symptoms is even higher, up to $25 \%$ during the last trimester of pregnancy, according to a recent metaanalysis. ${ }^{12}$ Pregnancy distress has been associated with several aspects of poor pregnancy outcome, including pregnancy-induced hypertension, PTB and SGA. ${ }^{13-17}$ Poor maternal thyroid function has also been associated with increased depressive symptoms during the pregnancy. ${ }^{18} 19$ A protective factor against negative effects of depressive symptoms may be mindfulness, as shown before. ${ }^{20}$ Nonreacting was positively associated with birth weight.

Coping with perinatal changes is likely to be particularly challenging for women who experience a high need for control and predictability. ${ }^{21}$ In the general population, an important determinant of depression is obsessivecompulsive personality disorder (OCPD). ${ }^{22} 23$ As such, expecting mothers with OCPD might be at an increased risk of distress symptoms during gestation. So far, OCPD has hardly been investigated in association with maternal mental health. ${ }^{24}$

Another predictor of mental health in general is attachment style. Adult attachment style is defined as the systematic pattern of relational expectations, emotions and behaviours that results from the internalisation of a particular attachment history. ${ }^{25}{ }^{26}$ Individuals who are insecurely attached tend to have relationships of lower quality, report lower marital satisfaction, experience higher levels of stress and are at increased risk of depression. $^{27}$ Maternal attachment insecurity has also been linked with negative parenting characteristics and child outcomes $^{28}$ and it may, therefore, be related to affective feelings toward the child during the pregnancy and the postpartum period. This may in turn trigger poor mother-infant bonding and may interfere with the child's emotional development.

\section{Partner relationship}

The birth of a child is one of the most invasive events in a romantic relationship. Previous research has shown that the transition to parenthood sets off significant changes in partners' satisfaction with their relationship. ${ }^{29} 30$ Typically, these studies showed that marital satisfaction increases during pregnancy (coined as the "honeymoon effect'), ${ }^{31}$ after which it declines steeply directly after childbirth. ${ }^{31}{ }^{32}$ In this project, we aim to unravel which groups of parents are especially at risk of becoming less happy with their relationship in the transition to parenthood. Subsequently, we aim to develop interventions aimed at protecting the quality of their relationship.

\section{Work}

The majority of pregnant women in the Netherlands has a paid job. Contrary to most other European countries, women return to work already at around 12 weeks post partum. The partner has as little as 1-week leave post partum. Recent research by the Statistics Netherlands has shown that $15 \%$ of the Dutch working population suffers from mental or emotional exhaustion due to work (burn-out symptoms). ${ }^{33}$ These symptoms are particularly prevalent among young women between 25 and 35 years old $(18 \%) .{ }^{33}$ Moreover, women between 25 and 45 years are twice as likely to be absent from work compared with men. This difference can partly be explained by physical and psychological problems during the pregnancy and post partum. ${ }^{34}$ In the current study, physical and psychological factors affecting workrelated well-being and performance of women during the pregnancy and the postpartum period will be investigated.

\section{Objectives}

The primary objective of the Brabant study is to investigate whether obstetric outcomes (PE, PTB, gestational diabetes mellitus (GDM), SGA, term of gestation at 
Table 1 Time points for the measures

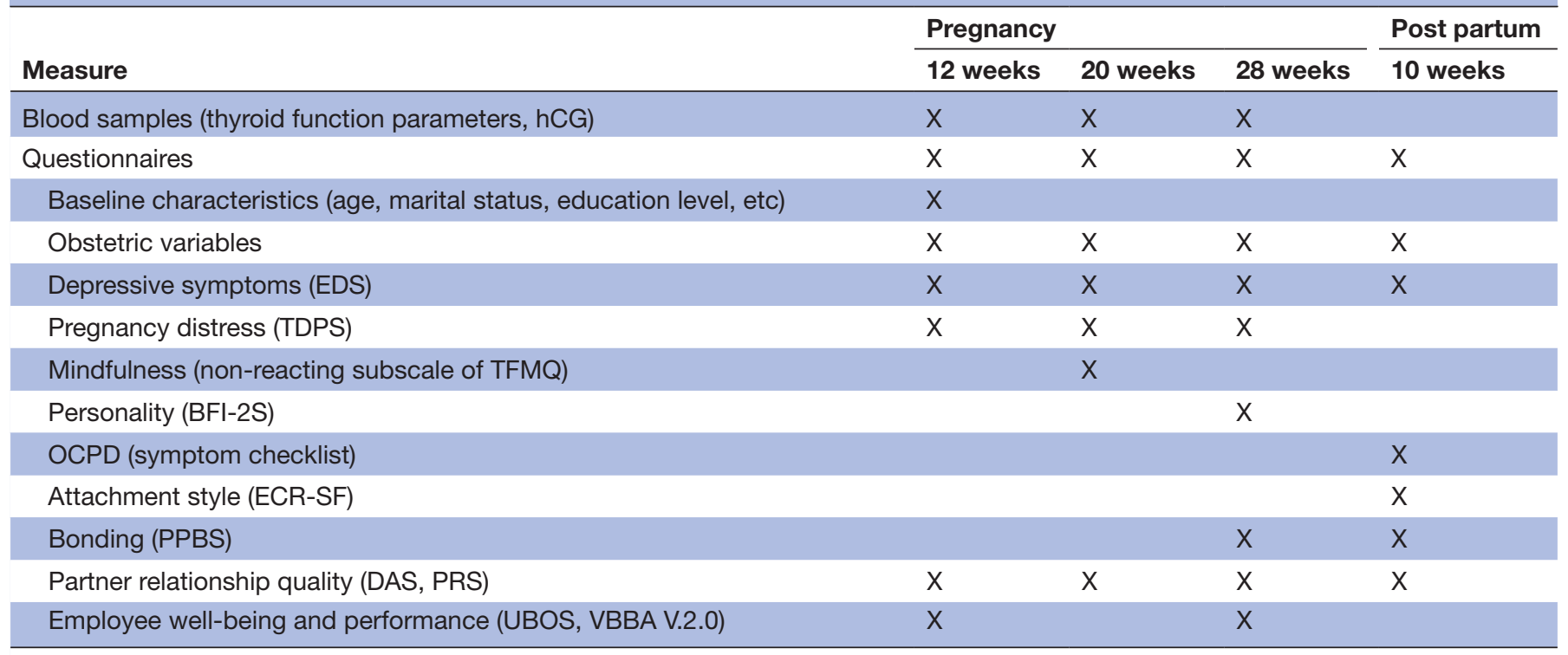

BFI, Big Five Inventory; DAS, Dyadic Adjustment Scale; ECR-SF, Experiences in Close Relationships Scale Short Form; EDS, Edinburgh Depression Scale; hCG, human chorionic gonadotrophin; OCPD, obsessive-compulsive personality disorder; PPBS, Postnatal Bonding Scale; PRS, Partner Responsiveness Scale ; TDPS, Tilburg Pregnancy Distress Scale; TFMQ, Three Facet Mindfulness Questionnaire; UBOS, Utrecht Burnout Scale; VBBA, Vragenlijst Beleving en Beoordeling van de Arbeid.

delivery, mode of delivery) are related to different trajectories of gestational thyroid function. The secondary objective is to investigate how different trajectories of pregnancy distress are related to obstetric outcome, and the role of personality in this association. Tertiary objective is to evaluate the possible association between thyroid dysfunction and pregnancy distress. A fourth objective is to evaluate the possible role of maternal distress and attachment style on maternal-fetal bonding and to study the social changes in the perinatal period with regard to partner relationship. Finally, we will investigate the effect of mental health during pregnancy on well-being and performance at work.

\section{METHODS AND ANALYSIS \\ Design and setting}

The current study is a longitudinal, prospective cohort study among pregnant women, from 12 weeks pregnancy up until 10 weeks post partum with a clear option of prospective follow-up including the children until preschool age. The current paper describes the perinatal part of the Brabant study. Pregnant women will be recruited among community midwife practices in the South-East part of the North-Brabant province in the Netherlands (Tilburg, Eindhoven and Den Bosch). In this area, 15 000 pregnancies occur annually. The regional organisation responsible for blood collection for primary and secondary care laboratories (De Bloedafname) will perform blood sample collection. The laboratory of clinical chemistry and haematology of the Máxima Medical
Centre Veldhoven is responsible for analysis of TSH, fT4, TPO-Ab and hCG and storage of the blood samples.

\section{Recruitment}

In the Netherlands, about $84 \%$ of pregnant women start antenatal care in a midwife practice, the other $16 \%$ are high risk and start within the hospital setting. ${ }^{35}$ Considering early abortion rate and the exclusion criteria, it is estimated that around 9000 pregnant women will be eligible for participation each year. Pregnant women (18+ years) who have an understanding of the Dutch or English language and have their first antenatal visit before 12 weeks gestation are eligible for participation.

Exclusion criteria are: multiple pregnancy, known endocrine disorder before pregnancy (other than thyroid function problems), diabetes type I, rheumatoid arthritis, severe psychiatric disease (schizophrenia, bord00erline or bipolar disorder), HIV, drug or alcohol addiction problems or any other disease resulting in treatment with drugs that are potentially adverse for the fetus and need careful follow-up during the pregnancy. Moreover, women must have access to the internet.

Pregnant women visit the community midwife for the first time around 6-8 weeks gestation. During this visit, eligible pregnant women will be informed, both orally and written, about the study by their midwife. When they agree to participate, they will sign a full written informed consent. In the past 25 years, five cohorts of pregnant women have been formed in the same area with the same design showing an average response rate between $70 \%$ and $76 \% .{ }^{36}$ Recruitment started with a pilot in 2018 and 
is now ongoing. Recruitment is expected to be finished mid-2022.

\section{Patient and public involvement}

Lessons learnt from previous pregnant cohorts in the same area were used during the design of the current study. ${ }^{36}$ Midwives and pregnant women evaluated the design and questionnaires during a pilot, after which appropriate adjustments were made. Participants will be informed about the results of the Brabant study via email.

\section{Sample size calculation}

An important variable of research of the Brabant study is the occurrence of obstetric complications (PE, PTB, SGA and GDM). The sample size calculation is mainly based on the possible relation between different trajectories of thyroid function and these obstetric complications. In a previous LCA analysis of a cohort of 1100 pregnant women, $8 \%$ of women belonged to 'abnormal' trajectories at risk for poor thyroid function during the pregnancy and consequently at risk for obstetric complications. Obstetric complications were 2-3 times more prevalent in these two 'abnormal' trajectories compared with the reference group (92\% of women) ${ }^{37}$ This cohort of women was from the same area as the current study, therefore, we expect similar outcomes. The sample size needed for statistically and clinically relevant differences between the two groups can be calculated according to Cohen. ${ }^{38}$ For example, PE is expected to occur in $4 \%$ of the women of the reference group, reflecting $92 \%$ of the total sample. PE is expected to occur in $8 \%$ of the women of the other two trajectories, reflecting $8 \%$ of the total sample. With an alpha of 0.05 and beta of 0.80 , the sample size of both groups should be 200 women. ${ }^{38}$ Similar or higher prevalence figures are known for PTB, SGA and GDM. ${ }^{39}$

With a sample of 4000 at baseline and an expected drop-out of $10 \%,{ }^{40}$ all obstetric data will be available of 3600 women. Of these, $8 \% \quad(n=288)$ will belong to the two high-risk trajectories. This $\mathrm{N}$ meets the 200 required.

The prevalence of women with high depressive symptomatology is substantially higher than PE, PTB and SGA and varies between $10 \%$ and $15 \%$ according to the pregnancy trimester. ${ }^{41}$ The prevalence for self-reported anxiety symptoms during the pregnancy is between $18 \%$ and $25 \% .{ }^{12}$ These figures are large enough to perform statistical analysis with adequate power looking at a possible association with thyroid function trajectories. LCA will also be used to evaluate different trajectories of depressive symptomatology throughout gestation in relation to thyroid function and obstetric outcome.

Prevalence figures of both thyroid dysfunction and pregnancy distress during gestation are adequate to evaluate a possible association between these conditions with sufficient epidemiological power.

\section{Data collection}

Participants will receive questionnaires by email three times during the pregnancy and will provide three blood samples during the pregnancy (both around 12, 20 and 28 weeks). Moreover, all participants will be asked to complete a questionnaire at 8-10 weeks post partum (see table 1). If necessary, women will receive a maximum of two reminder emails within 2 weeks after receiving the questionnaire.

During the regular blood sampling at 12 and 28 weeks, additional blood will be collected for the Brabant study. At 20 weeks, during the regular ultrasound check-up, women will also be asked to provide a blood sample. Blood samples will be analysed for thyroid function parameters and hCG. Women with thyroid dysfunction (expected $n=1 \%$ ), who according to the literature need immediate treatment, will be contacted by their midwife. ${ }^{5}$ At 10 weeks post partum, women will receive another questionnaire with additional questions regarding the birth and health of the newborn child. Data from the questionnaires will be downloaded automatically to the appropriate file types. All data will be coded and stored separately from identifiable participant information (names, addresses, birth dates, etc).

\section{Measures}

Thyroid function parameters

TSH, fT4, TPO-Ab and hCG will be measured in serum using electrochemiluminescence assays (Cobas e 601, Roche Diagnostics, Mannheim Germany). The anti-TPO assay is standardised in relation to the International Reference Preparation for anti-TPO MRC 66/387. A TPO-Ab titre $>35 \mathrm{IU} / \mathrm{mL}$ at 12 weeks gestation will be used as cut-off. This is a widely used cut-off in the literature. ${ }^{5}$

The reference range for trimester-specific normal thyroid function has recently been defined in 2200 pregnant women in the same area. ${ }^{42}$ Following the international guidelines of the American Thyroid Association and the American Endocrine Society, women with hypothyroidism that requires treatment $(\mathrm{TSH}>3.9 \mathrm{mIU} / \mathrm{L}$ and $\mathrm{fT} 4<11.2 \mathrm{pmol} / \mathrm{L}$, or $\mathrm{TSH}>10 \mathrm{mIU} / \mathrm{L}$ and $\mathrm{fT} 4$ within reference range) and overt hyperthyroidism (TSH $<0.19 \mathrm{mIU} / \mathrm{L}$ and $\mathrm{fT} 4>18.0 \mathrm{pmol} / \mathrm{L}$ ) will be identified. These cut-offs of both TSH and fT4 refer to the 2.5th and 97.5th percentiles assessed in TPO-Ab negative women at 12 weeks gestation. These women will be referred to their midwife or obstetrician. It is well known that during pregnancy, there are no cut-offs for hCG.

\section{Obstetric data}

All relevant data on pregnancy and delivery will be collected from the obstetric record form from the community midwife and/or the obstetrician. Obstetric parameters during the pregnancy such as blood pressure, weight gain, smoking habits and alcohol intake, and obstetric data such as gestational age at birth, usage of anaesthesia, mode of delivery, duration of labour, complications and birth weight will be assessed. 


\section{Depressive and NA symptoms}

The 10-item Edinburgh Depression Scale (EDS) will be used to measure symptoms of depression during the pregnancy. It is the most widely used instrument in perinatal research ${ }^{43}$ and has also been validated in Dutch postpartum women, ${ }^{44} 45$ as well as pregnant women. ${ }^{46}$ The items are answered on a 4-point Likert scale and higher total scores indicate more depressive symptoms.

Moreover, the Tilburg Pregnancy Distress Scale (TPDS) will be used. ${ }^{47}$ This 16 -item scale assesses partner involvement (PI, 5 items) and negative affect (NA, 11 items) including symptoms of worrying about pregnancy and labour. PI, the way a woman perceives her partner to be involved in her pregnancy, has been shown to be a protective factor against mental distress. ${ }^{40}$ The items are answered on a 4-point Likert scale and higher total scores indicate more symptoms of NA and less PI, respectively. The TDPS was reported as excellent by other research groups $^{48}$ and further research confirmed adequate its psychometric properties. ${ }^{48}$

Mindfulness (as an emotion-regulation strategy) will be assessed at 20 weeks using the 4-item non-reacting subscale of the Three Facet Mindfulness QuestionnaireShort Form (TFMQ-SF), ${ }^{49}$ which is originally derived from the short form of the frequently used Five Facet Mindfulness Questionnaire. ${ }^{50}$ The items are answered on a 5-point Likert scale and higher total scores indicating better mindfulness skills. The TFMQ-SF has previously been validated in pregnant women. ${ }^{49}$

\section{Personality traits}

Specific personality traits have been associated with physical and psychological issues during the pregnancy, such as preterm labour, perinatal insomnia and use of medication, alcohol and smoking. ${ }^{51-53}$ Therefore, in the current study, personality will be assessed using the 30-item Next Big Five Inventory (BFI-2S), which measures the Big Five personality dimensions (extraversion, agreeableness, conscientiousness, negative emotionality and open-mindedness). The BFI-abbreviated version is a valid and reliable questionnaire to asses Big Five personality traits. ${ }^{54}$

We previously developed an OCPD symptom checklist during pregnancy. The seven items are answered on a 4-point Likert scale and higher total scores indicating more symptoms of OCPD. This 7-item questionnaire showed adequate psychometric properties and highly significant correlations with EDS scores. ${ }^{55}$ Moreover, follow-up research in a sub-sample of postpartum women of this cohort showed that OCPD scores were rather stable over a period of 3 years with $r$ coefficients between 0.62 and $0.72 .^{56}$

\section{Adult attachment style}

The Experiences in Close Relationships Scale SF (ECR$\mathrm{SF})$ questionnaire is a well-validated questionnaire for measuring the underlying dimensions of attachment in adult relationships. ${ }^{57}$ The ECR-SF is designed to assess individual differences with respect to attachment-related anxiety and attachment-related avoidance, as measured with two subscales (each six items). Higher scores on the ECR-SF denote an insecurely attached person. Lower scores represent a securely attached person. All items are measured on a 7-point numerical scale ranging from 1 (strongly disagree) to 7 (strongly agree).

\section{Maternal-fetal bonding}

Maternal-fetal bonding will be assessed using the 5-item Prenatal and Postnatal Bonding Scale (PPBS). ${ }^{58}$ The scale consists of only positive statements to describe maternal feelings towards her (unborn) child, which can be answered on a 4-point Likert scale. A higher score reflects a better mother-fetal bonding. The PPBS showed to be a robust instrument with excellent psychometric properties.

\section{Partner relationship quality}

Relationship quality will be assessed with two different indicators: an 8-item version of the Dyadic Adjustment Scale ${ }^{59}$ aimed to assess the overall satisfaction with the relationship, and a 5-item version of the Partner Responsiveness Scale, ${ }^{60}$ aimed to assess the extent to which one partner experiences the other partner to constructively respond to his/her needs. Both these questionnaires have been used in previous research that studied the development of romantic relationships over time (see eg, Pollmann $e t a l^{61}$ and Vohs $e t a l^{62}$ ), and showed good reliability.

\section{Employee well-being and employee performance}

Work engagement will be measured with an ultra-short version of the Utrecht Work Engagement Scale. ${ }^{63}$ The 7-point Likert answer scale ranges from 1 (never) to 7 (always). The scale has shown appropriate reliability and validity. Burn-out will be measured with three items taken from the 5-item exhaustion subscale of the Utrecht Burn-out Scale. ${ }^{64}$ The 7-point Likert answer scale also ranges from 1 (never) to 7 (always). Internal consistency, test-retest reliability and factorial validity for the 5-item version were found to be adequate in prior research. ${ }^{6465}$ The employee's relationship with her supervisor is assessed by two items taken from the 6-item 'relationship with direct supervisor' subscale of the Vragenlijst Beleving en Beoordeling van de Arbeid (VBBA V.2.0) ${ }^{6566}$ The employee's relationship with her colleagues is assessed by two items taken from the 6-item 'relationship with colleagues' subscale of the VBBA V.2.0. ${ }^{66}{ }^{67}$ The two items of both subscales reflect the atmosphere/relationship quality dimension of the original scale. The original scale has adequate reliability and validity. Task and contextual performance are measured with three items taken from the Individual Work Performance Questionnaire using a 5-point Likert scale ranging from one (seldom) to five (always). ${ }^{68}$ The questionnaire has been found to be reliable ${ }^{69}$ and to display acceptable convergent and discriminant validity. ${ }^{68}$ 


\section{Confounders}

Confounders used in this study include standard baseline characteristics (demographics, education, lifestyle habits such as smoking, alcohol and body mass index, BMI) a previous history of (family) thyroid function disease or depression/anxiety, typical pregnancy related symptoms such as morning-sickness symptoms (using the PregnancyUnique Quantification of Emesis). ${ }^{70}$ This information will be collected using self-report via the questionnaires. Moreover, the obstetric record forms will be critically evaluated for the occurrence of possible complications during pregnancy and labour. It is well known that apart from baseline BMI, inappropriate weight gain is an important determinant of both PE and GDM. The national institute of medicine of the US has defined inappropriate weight gain as the relative weight gain in relation to baseline BMI. ${ }^{71}$

\section{Statistical analyses}

Descriptive data will be presented as frequencies and corresponding percentages or means and SD. Differences between groups will be analysed using t-tests for continuous variables and $\chi^{2}$-tests for categorical variables. A $\mathrm{p}<0.05$ will be considered significant. Effect sizes of the corresponding statistics will be analysed. Missing data will be imputed using multiple imputation using the SPSS version 25 .

To study trajectories of gestational thyroid function, we will perform LCA using MPlus V.7.4. ${ }^{72} \mathrm{LCA}$ is a longitudinal mixture modelling technique that can identify homogeneous classes within a larger heterogeneous longitudinal data sample. To model thyroid function, we will include TSH and fT4 at all trimesters. ${ }^{72}$ Since three time points were included, only linear growth factors can be estimated. The starting point will be a one-class model, after which models will be fitted to increasing numbers of classes. To determine the optimal number of classes, we will apply the following fit indices: Bayesian information criterion, Lo-Mendell-Rubin likelihood ratio test and Bootstrapped likelihood ratio test. ${ }^{73}$ Apart from these fit indices, we will also consider entropy, with entropy values closer to 1 indicating clearer delineation of classes. ${ }^{74} \mathrm{We}$ will further account for parsimony and interpretability of the models, and average posterior probabilities of their classes. We will also take into account whether additional classes include more than $1 \%$ of the total sample. We will use this statistical approach both for changes of thyroid function as well as pregnancy distress symptoms assessed at three different trimester throughout gestation.

The possible relation of these three trajectories with obstetric outcome will be investigated using multiple (multinominal) logistic regression, adjusting for age, parity, maternal educational level and EDS score, with appropriate adjustments for non-normality if necessary. Similarly, multiple linear regression will be used to evaluate the possible association of these thyroid trajectories and the depression scores. A similar technique will be applied to assess trajectories of symptoms of depression (EDS), PI and NA. To model the trajectories of these variables, three time points during the pregnancy will be included, using the same LCA methodology as for thyroid function, as described above. We will compare the prevalence of different thyroid function trajectories between the different trajectories of pregnancy distress symptoms using $\chi^{2}$ tests.

\section{ETHICS AND DISSEMINATION}

The Brabant study has been approved by the Medical Ethical Committee of the Máxima Medical Center Veldhoven (protocol number NL64091.015.17). Women will be provided with verbal and written information about the study and will sign a written informed consent when they agree to participate. During the design of the study, special attention was given to the length and nature of the questionnaires, in order to minimalise the burden on the participants. Moreover, two of the three blood samples overlap with the blood samples collected as part of the regular obstetric care, meaning women only need one extra venipuncture, which limits the burden for the participants. Data management will adhere to strict guidelines in compliance with General Data Protection Regulation of the European Union. Results of the study will be submitted to peer reviewed journals in the relevant fields and presented on national and international conferences. These will be drafted according to Strengthening of the Reporting of Observational Studies in Epidemiology reporting guidelines.

\section{DISCUSSION}

The extensive perinatal literature is hampered by many studies using a cross-sectional design, especially when psychological and/or obstetric outcome are linked to possible biological determinants. Moreover, the very recent literature of impaired maternal thyroid function in relation to obstetric outcome shows an intriguing paradox: on the one hand, four large randomised controlled trials failed to show any benefit of thyroid hormone treatment during gestation on either obstetric or developmental outcomes. ${ }^{75-78}$ On the other hand, a recent meta-analysis in over 40000 pregnant women showed a clear association between poor thyroid function and preterm birth and the similar consortium showed an association with poor thyroid function and birth weight. ${ }^{79} 80$ Apart from possible explanations reported in the literature (intervention started too late), it might be possible that we need further differentiation or more accurate definition of subgroups of women with an abnormal pattern of thyroid function throughout pregnancy who might benefit from an intervention. LCA might contribute to a more accurate definition of the targeted group using a prospective approach rather than a cross-sectional approach.

The major strength of the Brabant study is the aim to overcome these limitations using a prospective design with repeated measurements in a large sample of pregnant women, assessing both psychological and biological 
parameters. The large sample size will enable to look at possible associations between psychological and physiological determinants and obstetric complications that are relatively rare (PE, PTB, SGA), also in primiparous and multiparous women separately, using advanced statistics including LCA. This latter technique will also enable to look at a possible association between thyroid function and distress symptoms in a prospective way. Moreover, the feasibility of the Brabant study is realistic because of the extensive experience of the perinatal research group of Tilburg University that formed up to six pregnancy and postpartum cohorts in the past 30 years, varying from 300 to 2200 women. Over this 30 -year period-in the same area as the current study-the participation rate was persistently between $70 \%$ and $75 \%$ with a drop-out of $7 \%-10 \%$ during the pregnancy. In the current study, all women provide written informed consent to track obstetrical outcomes in the medial record forms. This will result in objective obstetric information detected during clinical practice by midwives and obstetricians. All questionnaires will be completed online with no (face-to-face or telephone) interviews. This limits the possible outcome with regard to syndromal diagnosis of depression and anxiety.

In conclusion, there is a need for longitudinal cohort studies with multiple measurements in large samples of pregnant women. The current study will contribute with a comprehensive and in-depth study of factors affecting obstetric outcome, including thyroid function and pregnancy distress, and other important psychological and social changes, such as the partner relationship and well-being and performance at work during the perinatal period.

\section{Author affiliations}

${ }^{1}$ CoRPS - Center of Research on Psychological and Somatic disorders, Department of Medical and Clinical Psychology, Tilburg University, Tilburg, The Netherlands

${ }^{2}$ Department of Human Resource Studies, Tilburg University, Tilburg, The

Netherlands

${ }^{3}$ Department of Social Psychology, Tilburg University, Tilburg, The Netherlands ${ }^{4}$ Laboratory of Clinical Chemistry and Hematology, Maxima Medical Center, Veldhoven, The Netherlands

${ }^{5}$ Clinical Laboratory, Diagnostiek voor U, Eindhoven, The Netherlands

${ }^{6}$ Department of Obstetrics and Gynecology, Maxima Medical Center, Eindhoven, The Netherlands

${ }^{7}$ Department of Developmental Psychology, Tilburg University, Tilburg, The Netherlands

Acknowledgements We would like to thank 'Verloskundig Consortium Zuid-0ost Brabant' for their support and participation in the recruitment of participants for the Brabant study.

Contributors The conception and design of this study was principally developed by VP. All authors contributed to the design. MM, LH and GO contributed to the data collection and organisation of planning and logistics. MB and KN contributed to the collection and analysis of the blood samples. MM and VP drafted the manuscript, with contributions from MR, CM, TP and SB. All authors critically revised and approved the final manuscript.

Funding The authors have not declared a specific grant for this research from any funding agency in the public, commercial or not-for-profit sectors.

Competing interests None declared.

Patient and public involvement Lessons learnt from previous pregnant cohorts in the same area were used during the design of the current study. Midwives and pregnant women evaluated the design and questionnaires during a pilot, after which appropriate adjustments were made.
Patient consent for publication Not required.

Provenance and peer review Not commissioned; externally peer reviewed.

Open access This is an open access article distributed in accordance with the Creative Commons Attribution Non Commercial (CC BY-NC 4.0) license, which permits others to distribute, remix, adapt, build upon this work non-commercially, and license their derivative works on different terms, provided the original work is properly cited, appropriate credit is given, any changes made indicated, and the use is non-commercial. See: http://creativecommons.org/licenses/by-nc/4.0/.

ORCID iD

Margreet Meems http://orcid.org/0000-0002-0938-3840

\section{REFERENCES}

1 Kuppens SMI, Hasaart THM, van der Donk MWP, et al. [Fewer caesarean sections for breech presentation following external cephalic version according to a protocol in a special office visit]. Ned Tijdschr Geneeskd 2008;152:1323-8.

2 Moog NK, Entringer S, Heim C, et al. Influence of maternal thyroid hormones during gestation on fetal brain development. Neuroscience 2017;342:68-100.

3 Wilson KL, Casey BM, Mclntire DD, et al. Subclinical thyroid disease and the incidence of hypertension in pregnancy. Obstet Gynecol 2012;119:315-20.

4 Korevaar TIM, Medici M, Visser TJ, et al. Thyroid disease in pregnancy: new insights in diagnosis and clinical management. Nat Rev Endocrinol 2017;13:610-22.

5 Alexander EK, Pearce EN, Brent GA, et al. 2017 guidelines of the American thyroid association for the diagnosis and management of thyroid disease during pregnancy and the postpartum. Thyroid 2017;27:315-89.

6 Jung T, Wickrama KAS. An introduction to latent class growth analysis and growth mixture modeling. Soc Personal Psychol Compass 2008;2:302-17.

7 Pop V, Broeren M, Wijnen $\mathrm{H}$, et al. Longitudinal trajectories of gestational thyroid function: a new approach to better understand changes in thyroid function. $J$ Clin Endocrinol Metab 2018;103:2889-900.

8 Korevaar TIM, Steegers EAP, Pop VJ, et al. Thyroid autoimmunity impairs the thyroidal response to human chorionic gonadotropin: two population-based prospective cohort studies. J Clin Endocrinol Metab 2017;102:69-77.

9 Riecher-Rössler A, Hofecker Fallahpour M. Postpartum depression: do we still need this diagnostic term? Acta Psychiatr Scand Suppl 2003;418:51-6.

10 Marcus SM, Flynn HA, Blow FC, et al. Depressive symptoms among pregnant women screened in obstetrics settings. $J$ Womens Health 2003;12:373-80.

11 Meijer JL, Bockting CLH, Stolk RP, et al. Associations of life events during pregnancy with longitudinal change in symptoms of antenatal anxiety and depression. Midwifery 2014;30:526-31.

12 Dennis C-L, Falah-Hassani K, Shiri R. Prevalence of antenatal and postnatal anxiety: systematic review and meta-analysis. $\mathrm{Br} \mathrm{J}$ Psychiatry 2017;210:315-23.

13 Alder J, Fink N, Bitzer J, et al. Depression and anxiety during pregnancy: a risk factor for obstetric, fetal and neonatal outcome? A critical review of the literature. J Matern Fetal Neonatal Med 2007;20:189-209.

14 Andersson L, Sundström-Poromaa I, Wulff M, et al. Implications of antenatal depression and anxiety for obstetric outcome. Obstet Gynecol 2004;104:467-76.

15 Grote NK, Bridge JA, Gavin AR, et al. A meta-analysis of depression during pregnancy and the risk of preterm birth, low birth weight, and intrauterine growth restriction. Arch Gen Psychiatry 2010;67:1012-24.

16 Staneva A, Bogossian F, Pritchard M, et al. The effects of maternal depression, anxiety, and perceived stress during pregnancy on preterm birth: a systematic review. Women Birth 2015;28:179-93.

17 Zhu P, Tao F, Hao J, et al. Prenatal life events stress: implications for preterm birth and infant birthweight. Am J Obstet Gynecol 2010;203:34.e1-8.

18 Bunevicius R, Kusminskas L, Mickuviene N, et al. Depressive disorder and thyroid axis functioning during pregnancy. World $\mathrm{J}$ Biol Psychiatry 2009;10:324-9.

19 Kuijpens JL, Vader HL, Drexhage HA, et al. Thyroid peroxidase antibodies during gestation are a marker for subsequent depression postpartum. Eur J Endocrinol 2001;145:579-84. 
20 Nyklíček I, Truijens SEM, Spek V, et al. Mindfulness skills during pregnancy: prospective associations with mother's mood and neonatal birth weight. J Psychosom Res 2018;107:14-19.

21 Grilo CM, Stout RL, Markowitz JC, et al. Personality disorders predict relapse after remission from an episode of major depressive disorder: a 6-year prospective study. J Clin Psychiatry 2010;71:1629-35.

22 Diedrich A, Voderholzer U. Obsessive-compulsive personality disorder: a current review. Curr Psychiatry Rep 2015;17:2.

23 Grant JE, Mooney ME, Kushner MG. Prevalence, correlates, and comorbidity of DSM-IV obsessive-compulsive personality disorder: results from the National epidemiologic survey on alcohol and related conditions. J Psychiatr Res 2012;46:469-75.

24 van Broekhoven KEM, Karreman A, Hartman EE, et al. Obsessivecompulsive personality disorder symptoms as a risk factor for postpartum depressive symptoms. Arch Womens Ment Health 2019;22:475-83.

25 Fraley RC, Shaver PR. Adult romantic attachment: theoretical developments, emerging controversies, and unanswered questions. Rev Gen Psychol 2000;4:132-54.

26 Mikulincer M, Shaver PR. Attachment theory and emotions in close relationships: exploring the attachment-related dynamics of emotional reactions to relational events. Pers Relatsh 2005;12:149-68.

27 Atkinson L, Paglia A, Coolbear J, et al. Attachment security: a meta-analysis of maternal mental health correlates. Clin Psychol Rev 2000;20:1019-40.

28 Jones JD, Cassidy J, Shaver PR. Parents' self-reported attachment styles: a review of links with parenting behaviors, emotions, and cognitions. Pers Soc Psychol Rev 2015;19:44-76.

29 Mitnick DM, Heyman RE, Smith Slep AM. Changes in relationship satisfaction across the transition to parenthood: a meta-analysis. $J$ Fam Psychol 2009;23:848-52.

30 Twenge JM, Campbell WK, Foster CA. Parenthood and marital satisfaction: a meta-analytic review. J Marriage Fam 2003;65:574-83.

31 Doss BD, Rhoades GK, Stanley SM, et al. The effect of the transition to parenthood on relationship quality: an 8 -year prospective study. $J$ Pers Soc Psychol 2009;96:601-19.

32 Don BP, Mickelson KD, Rhoades GK. Relationship satisfaction trajectories across the transition to parenthood among low-risk parents. J Marriage Fam 2014;76:677-92.

33 Statistics Netherlands. Jonge vrouwen relatief vaak vermoeid door werk, 2018. Available: https://www.cbs.nl/nl-nl/nieuws/2018/07/ jonge-vrouwen-relatief-vaak-vermoeid-door-werk

34 Statistics Netherlands. Ziekteverzuim - cijfers \& context, 2017. Available: https://www.volksgezondheidenzorg.info/onderwerp/ ziekteverzuim/cijfers-context/huidige-situatie

35 Perined. Perinatale Zorg in Nederland 2015, 2016.

36 Pop V, van Son M, Wijnen $\mathrm{H}$, et al. Increase of depressive symptomatology during pregnancy over 25 years' time in four population based cohorts. J Affect Disord 2019;259:175-9.

37 Hansen PS, Brix TH, Sørensen TIA, et al. Major genetic influence on the regulation of the pituitary-thyroid axis: a study of healthy Danish twins. J Clin Endocrinol Metab 2004;89:1181-7.

38 Cohen J. Statistical power analysis for the behavioural sciences. 2nd edn. Lawrence Erlbaum Associates, 1988.

39 Perined. Perinatale Zorg in Nederland 2017. Utrecht, 2019.

40 Boekhorst MGBM, Beerthuizen A, Endendijk JJ, et al. Different trajectories of depressive symptoms during pregnancy. J Affect Disord 2019;248:139-46.

41 Truijens SEM, Spek V, van Son MJM, et al. Different patterns of depressive symptoms during pregnancy. Arch Womens Ment Health 2017;20:539-46.

42 Pop V, Broeren M, Wiersinga W. The attitude toward hypothyroidism during early gestation: time for a change of mind? Thyroid 2014;24:1541-6.

43 O'Connor E, Rossom RC, Henninger M, et al. Primary care screening for and treatment of depression in pregnant and postpartum women: evidence report and systematic review for the US preventive services Task force. JAMA 2016;315:388-406.

44 Cox JL, Holden JM, Sagovsky R. Detection of postnatal depression. Development of the 10-item Edinburgh postnatal depression scale. Br J Psychiatry 1987;150:782-6.

45 Pop VJ, Komproe IH, van Son MJ. Characteristics of the Edinburgh post natal depression scale in the Netherlands. J Affect Disord 1992;26:105-10.

46 Bergink V, Kooistra L, Lambregtse-van den Berg MP, et al. Validation of the Edinburgh depression scale during pregnancy. J Psychosom Res 2011;70:385-9.

47 Pop VJM, Pommer AM, Pop-Purceleanu M, et al. Development of the Tilburg pregnancy distress scale: the TPDS. BMC Pregnancy Childbirth 2011;11:80.
48 Evans K, Spiby H, Morrell CJ. A psychometric systematic review of self-report instruments to identify anxiety in pregnancy. $J$ Adv Nurs 2015;71:1986-2001

49 Truijens SEM, Nyklíček I, van Son J, et al. Validation of a short form three facet mindfulness questionnaire (TFMQ-SF) in pregnant women. Pers Individ Dif 2016;93:118-24.

50 Baer RA, Smith GT, Hopkins J, et al. Using self-report assessment methods to explore facets of mindfulness. Assessment 2006;13:27-45

51 Dørheim SK, Garthus-Niegel S, Bjorvatn B, et al. Personality and perinatal maternal insomnia: a study across childbirth. Behav Sleep Med 2016;14:34-48.

52 Handelzalts JE, Krissi H, Levy S, et al. Personality, preterm labor contractions, and psychological consequences. Arch Gynecol Obstet 2016;293:575-82.

53 Ystrom E, Vollrath ME, Nordeng $\mathrm{H}$. Effects of personality on use of medications, alcohol, and cigarettes during pregnancy. Eur $\mathrm{J}$ Clin Pharmacol 2012;68:845-51.

54 Soto CJ, John OP, Short JOP. Short and extra-short forms of the big five Inventory-2: the BFI-2-S and BFI-2-XS. J Res Pers 2017;68:69-81.

55 Broekhoven K V, Hartman E, et al. The pregnancy ObsessionCompulsion-Personality disorder symptom checklist. J Psychol Psychother 2016;6:233.

56 van Broekhoven KEM, Karreman A, Hartman EE, et al. Stability of the pregnancy obsessive-compulsive personality disorder symptoms checklist. Arch Womens Ment Health 2018;21:117-20.

57 Wei M, Russell DW, Mallinckrodt B, et al. The Experiences in Close Relationship Scale (ECR)-short form: reliability, validity, and factor structure. J Pers Assess 2007;88:187-204.

58 Cuijlits I, van de Wetering AP, Potharst ES, et al. Development of a pre- and postnatal bonding scale (PPBS). J Psychol Psychother 2016;6:5.

59 Spanier GB. Measuring dyadic adjustment: new scales for assessing the quality of marriage and similar dyads. J Marriage Fam 1976;38:15-28.

60 Kubacka KE, Finkenauer C, Rusbult CE, et al. Maintaining close relationships: gratitude as a motivator and a detector of maintenance behavior. Pers Soc Psychol Bull 2011;37:1362-75.

61 Pollmann MMH, Finkenauer C, Begeer S. Mediators of the link between autistic traits and relationship satisfaction in a non-clinical sample. J Autism Dev Disord 2010;40:470-8.

62 Vohs KD, Finkenauer C, Baumeister RF. The sum of friends' and lovers' self-control scores predicts relationship quality. Soc Psychol Personal Sci 2011;2:138-45.

63 Schaufeli WB, Shimazu A, Hakanen J, et al. An ultra-short measure for work engagement: the UWES-3 validation across five countries. Eur J Psychologic Assess 2017.

64 Schaufeli WB, van Dierendonck D. Utrechtse burnout Schaal (UBOS): Handleiding. Amsterdam, 2000.

65 Schaufeli WB, Bakker AB, Demands J. Job demands, job resources, and their relationship with burnout and engagement: a multi-sample study. J Organ Behav 2004;25:293-315.

66 van Veldhoven M, Prins J, van der Laken PA, et al. VBBA2.0: update van de standaard voor vragenlijstonderzoek naar werk. welbevinden en prestaties 2014

67 van Veldhoven M, Meijman T. Het meten van psychosociale arbeidsbelasting Met Een vragenlijst: de vragenlijst beleving en beoordeling van arbeid (VBBA). Amsterdam, 1994.

68 Koopmans L, Bernaards CM, Hildebrandt VH, et al. Construct validity of the individual work performance questionnaire. J Occup Environ Med 2014;56:331-7.

69 Koopmans L, Bernaards C, Hildebrandt V, et al. Development of an individual work performance questionnaire. Int J Product Perform Manage 2012;62:6-28.

70 Ebrahimi N, Maltepe C, Bournissen FG, et al. Nausea and vomiting of pregnancy: using the 24-hour Pregnancy-Unique quantification of emesis (PUQE-24) scale. J Obstet Gynaecol Can 2009;31:803-7.

71 American College of Obstetricians and Gynecologists. ACOG Committee opinion no. 548: weight gain during pregnancy. Obstet Gynecol 2013;121:210-2.

72 Muthén LK, Muthén BO. Mplus User's Guide. 7th edn. Muthén \& Muthén, 1998-2015.

73 Nylund KL, Asparouhov T, Muthén BO. Deciding on the number of classes in latent class analysis and growth mixture modeling: a Monte Carlo simulation study. Struct Equat Model Multidisciplin J 2007;14:535-69.

74 Collins LM, Lanza ST. Latent class and latent transition analysis: with applications in the social, behavioral, and health sciences. John Wiley \& Sons, 2010. 
75 Casey BM, Thom EA, Peaceman AM, et al. Treatment of subclinical hypothyroidism or hypothyroxinemia in pregnancy. $N$ Engl J Med 2017;376:815-25.

76 Dhillon-Smith RK, Middleton LJ, Sunner KK, et al. Levothyroxine in women with thyroid peroxidase antibodies before conception. $N$ Eng J Med 2019;380:1316-25.

77 Lazarus JH, Bestwick JP, Channon S, et al. Antenatal thyroid screening and childhood cognitive function. $N$ Engl J Med 2012;366:493-501.

78 Wang $\mathrm{H}$, Gao $\mathrm{H}$, Chi $\mathrm{H}$, et al. Effect of levothyroxine on miscarriage among women with normal thyroid function and thyroid autoimmunity undergoing in vitro fertilization and embryo transfer: a randomized clinical trial. JAMA 2017;318:2190-8.

79 Consortium on Thyroid and Pregnancy - Study Group on Preterm Birth, Korevaar TIM, Derakhshan A, et al. Association of thyroid function test abnormalities and thyroid autoimmunity with preterm birth: a systematic review and meta-analysis. JAMA 2019;322:632-41.

80 Derakhshan A, Peeters RP, Taylor PN, et al. Association of maternal thyroid function with birthweight: a systematic review and individualparticipant data meta-analysis. Lancet Diabetes Endocrinol 2020;8:501-10. 